\title{
Stability Augmentation of a Fixed Speed Wind Generator by Using VSWT-PMSG
}

\author{
Zinat Tasneem*, M.R.I. Sheikh and A.N. Pinky
}

EEE Department, Rajshahi University of Engineering \& Technology, Rajshahi-6204, Bangladesh

\begin{abstract}
This paper proposes an optimized model of a variable speed wind turbine equipped with permanent magnet synchronous generator (VSWT-PMSG) which also has been used for the stability augmentation of a wind farm including fixed speed wind generators, like Induction generator (IG). An effective control strategy with two-level IGBT converterinverter set along with DC link capacitor and maximum power point tracking (MPPT) system assures the real power exchange to the grid and also a perfect reactive power compensation that maintains the grid side voltage constant. Moreover, it is shown that the proposed model can enhance the stability of a conventional IG based wind farm when used in combination with PMSG. Thus it eliminates the need of external controlling devices and makes the system simple and cost effective. A comparison for the stability augmentation capability between IG and PMSG has been explained. Both the dynamic and transient analyses of the proposed system have been carried out by using the laboratory standard power system software package, PSCAD/EMTDC.
\end{abstract}

Keywords: Reactive power compensation, IG, frequency converter, dynamic stability and transient stability.

\section{INTRODUCTION}

Renewable energy sources are now rapidly taking the places of non-renewable energy sources, since the non-renewable energy sources are limited and they are the main reason of green house effect and environment pollution. Among the renewable energy sources, wind is a promising one. It is currently one of the most cost effective ways to produce electricity. Worldwide there are now over two hundred thousand wind turbines operating, with a total nameplate capacity of 282,482 MW as of end 2012 [1]. Since, the demand for wind energy is increasing day by day, it is important to assure that the power developed by the wind farm must be of good quality and the operation of the wind farm must be stable [2]. As the wind speed is dynamic in nature, the output parameters of a wind farm like the terminal voltage, output power, frequency etc fluctuate with the wind speed. Again, the wind farm must have an enhanced transient stability, i.e. the farm will have the ability to respond to a disturbance or fault of the system from a normal operating condition and to return to a state where their operation is normal again as quickly as possible after the clearance of the fault. Therefore, both the dynamic stability and the transient stability of the wind farm should be assured.

Over recent years, a new scheme for the wind generators has become popular, which includes a Variable Speed Wind Turbine with Permanent Magnet Synchronous Generator (VSWT-PMSG). In this concept, PMSG can be directly driven by a wind turbine

*Address correspondence to this author at the EEE Department, Rajshahi University of Engineering \& Technology, Rajshahi-6204, Bangladesh;

Tel: +8801719533263; E-mail: tasneemzinat@gmail.com without gearbox and it is connected to the ac power grid through the power converters. In our previous study [3,4], it is seen that PMSG has the capability to control the real and reactive power, maintain the output voltage constant and also it is eligible to provide the necessary reactive power compensation during the transient condition, thus it can reduce the voltage and power fluctuations caused by the dynamic wind speed.

Therefore, in this study, these advantages of PMSG are taken into consideration for improving the output fluctuations of IG's. Hence, external storage systems can be ignored. It has been found in the simulation results that the proposed wind farm has a better dynamic stability as well as an enhanced transient stability. In that way, the necessary reactive power of the IG can be supplied to restore the electromagnetic torque. This strategy not only provides the terminal voltage regulation and output fluctuation minimization, but also increases the power producing capability of a wind farm. Moreover this model eliminates the need of any external controlling devices, which are generally non-producing elements for the wind farm and make the system more complicated and increase the system overall cost.

The recent years, some works have been done on a PMSG based wind farm. In [5] various combinations PMSG and its controlling circuits have been compared. Malfunctions of the controllers have neen considered. But, in this paper, PMSG has been used to enhance the stability and performance of a fixed speed IG based wind farm. It has been shown that PMSG can work both as a generator and as a controlling device. In [6] a PMSG based wind farm has been used to enhance the 
fault ride through capability of a fixed speed wind farm with a three-level IGBT converter-inverter set. In [7] a VSWT-PMSG has been used in HVDC connected offshore wind farm. Both the papers use a complex control strategy for the frequency converters control. Again a stabilization of a grid connected wind farm using PMSG is depicted in [2]. However multi-mass drive train model has not been considered. Therefore, a more practical case considering a dynamic wind speed with two-mass drive train model for transient stability analysis and a simple control strategy for frequency converters has been considered in this paper. It is seen that the proposed control strategy can enhance both dynamic and transient stability of a wind farm integrated power system.

\section{SYSTEM MODEL}

\subsection{Wind Turbine Model}

Wind Turbines are the prime element of a wind farm. They are used to convert wind energy into electrical energy. The modeling of wind turbine is very important. Various works have been done in this field by aerodynamic engineers. The model of wind turbine rotor is complicated. According to the blade element theory [8], modeling of blade and shaft needs complicated and lengthy computations. Moreover, it also needs detailed and accurate information about rotor geometry. Therefore, considering only the electrical behavior of the system, a simplified method of modeling of the wind turbine blade and shaft is normally used [9]. The mathematical relation for the mechanical power extraction from the wind can be expressed as follows [8].

$$
\operatorname{Pm}=\frac{1}{2} \rho \pi \mathrm{R}^{2} \mathrm{~V}_{\mathrm{w}}{ }^{3} \mathrm{C}_{\mathrm{P}}(\lambda, \beta)
$$

Where, $\mathrm{Pm}$ is the mechanical power that the turbine extracts from the wind, $\rho$ is the air density $\left(\mathrm{Kg} / \mathrm{m}^{3}\right), R$ is the blade radius $(m)$ and $C_{P}$ is the power coefficient which is a function of both, tip speed ratio, $\lambda$, and blade pitch angle, $\beta$ (deg). $\lambda$ and $C_{P}$ are expressed as [10]

$\lambda=\frac{\omega \mathrm{R}}{\mathrm{V}_{\mathrm{W}}}$

Where, $\omega$ is the wind turbine angular speed ( $\mathrm{rad} / \mathrm{s})$, $V w$ is the wind speed $(\mathrm{m} / \mathrm{s})$. The power coefficient, $C_{P}$ is [10]

$$
\mathrm{C}_{\mathrm{P}}=\frac{1}{2}\left(\Gamma-0.022 \beta^{2}-5.6\right) \mathrm{e}^{-0.17 \Gamma}
$$

Since, $C_{P}$ is expressed in feet and mile, $\Gamma$ is corrected as,

$$
\Gamma=\left(\frac{\mathrm{R}}{\lambda}\right) *\left(\frac{3600}{1609}\right)
$$

The torque coefficient, $\mathrm{C}_{\mathrm{T}}$, is given by

$$
\mathrm{C}_{\mathrm{T}}=\frac{\mathrm{C}_{\mathrm{P}}(\lambda)}{\lambda}
$$

The wind turbine torque is expressed as,

$$
\mathrm{T}_{\mathrm{m}}=\frac{1}{2} \rho \pi \mathrm{R}^{3} \mathrm{~V}_{\mathrm{w}}{ }^{2} \mathrm{C}_{\mathrm{T}}(\lambda)
$$

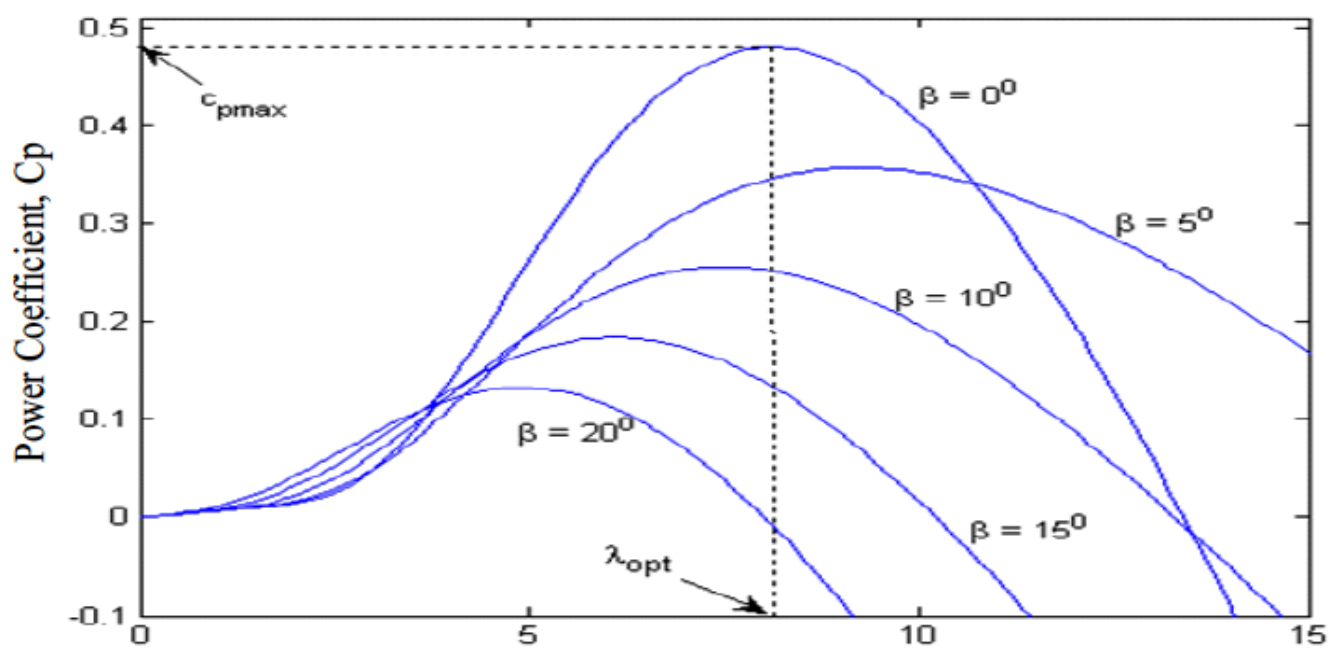

Tip speed ratio, $\lambda$

Figure 1: $C_{P}-\lambda$ characteristics for different pitch angle, $\beta$. 


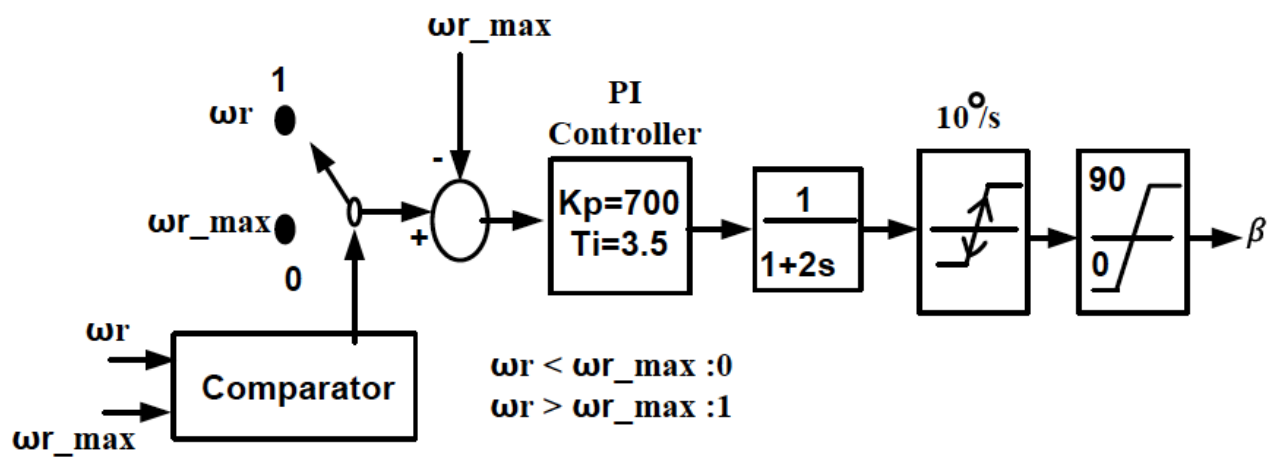

Figure 2: Pitch Controller used for PMSG.

The $C_{P}-\lambda$ characteristics, for different values of pitch angle $\beta$, are illustrated in the Figure 1 . The maximum value of $C_{P}$ i.e. $C_{\text {Popt }}=0.48$ is obtained for $\beta=0^{\circ}$ and $\lambda$ $=8.1$. This particular value of $\lambda$ is defined as the optimal value, $\lambda_{\text {opt }}$.

\subsection{Pitch Controller Model}

Pitch controller works when the wind speed exceeds the rated speed. If the rotor speed of PMSG is greater than the rated speed $\left(\omega_{r_{-} \max }=1 \mathrm{pu}\right)$ due to high wind speed, the pitch controller controls the rotational speed. Therefore the output of PMSG will not exceed the rated power. The pitch controller used in this model is shown in Figure 2. It is modeled with a first order delay system with a time constant of $2 \mathrm{sec}$. A rate limiter with a value $10 \% \mathrm{sec}$ is added, because generally, the pitch actuation system cannot respond instantly. A Proportional Integral (PI) controller is used in pitch control system. The proportional gain is chosen to be 700 and the time constant is 3.5 .

\subsection{PMSG Model}

Figure 3 shows a VSWT-PMSG system which is modeled with a fully controlled frequency converter. The PMSG model available in the package software PSCAD/EMTDC is used [11] in this study. The frequency converter consists of a generator side AC/DC converter, a DC link capacitor and a grid side $D C / A C$ inverter. Each of the converter/inverter is a standard three phase two-level unit, composed of six insulated gate bipolar junction transistor (IGBTs) and anti parallel diodes. The full-rating power converter is made up of two back- to-back IGBT bridges (the generator side converter and grid side inverter) linked by a DC bus.

The three phase AC output of the generator is rectified, and the DC output from the rectifier is fed to an IGBT-based grid side inverter. Its output is fed to a step-up transformer and then to the grid. The rating of the power converters corresponds to the rated power of

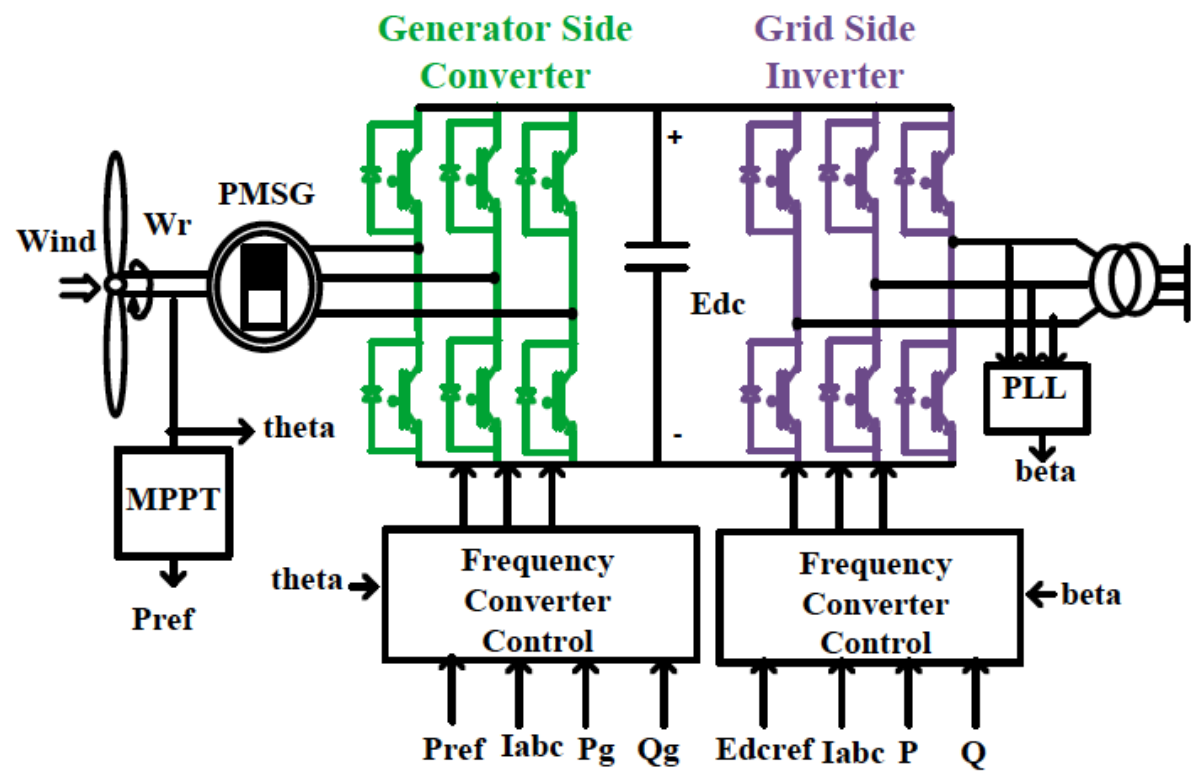

Figure 3: Electrical scheme of VSWT-PMSG. 
generator plus losses. The power converters control the power flow to the grid. Specific control strategies are used to control the frequency converter- inverter set. The control signal applied directly to IGBT's gate switching of the converters is three phase sinusoidal voltage. The three phase sinusoidal signal is converted into d-q axis signal. In both the converter and inverter, triangle signal is used as carrier wave of Pulse Width Modulation (PWM) operation. The carrier frequency is chosen $1000 \mathrm{~Hz}$. The DC link capacitor value is 50,000 $\mu \mathrm{F}$. The rated $\mathrm{DC}$ link voltage is $1 \mathrm{pu}$. Figure $\mathbf{4 a}$ shows the block diagram of generator side converter control scheme. It is composed of two branches, one is for the active power ( $\mathrm{Pl}-1$ and $\mathrm{Pl}-2$ ) and the other is for the reactive power control ( $\mathrm{PI}-3$ and $\mathrm{PI}-4)$. Because the stator voltage is oriented along the q-axis of the reference frame, hence the equation for the real and reactive power becomes,

$$
\begin{aligned}
& \mathrm{P}_{\mathrm{m} \_ \text {stator }}=\left(\mathrm{V}_{\mathrm{qm}} \_ \text {stator }\right) *\left(\mathrm{I}_{\mathrm{qm} \_ \text {stator }}\right) \\
& \mathrm{Q} \text { m_stator }=\left(\mathrm{V}_{\mathrm{qm} \_\_ \text {stator }}\right) *(\mathrm{I} \text { dm_stator })
\end{aligned}
$$

From Eq. 7 and Eq. 8, it is seen that the q-axis current, $I_{q m \_s t a t o r}$, can control the active power, $P_{m_{-} \text {stator }}$. The active power reference is obtained from the output $\left(P_{\text {ref }}\right)$ of the MPPT. The d-axis current, $I_{d m \text { stator, can }}$ control the reactive power, $Q_{m}$ stator. The reactive power reference is set to zero for unity power factor operation.

Figure $\mathbf{4 b}$ shows the block diagram of grid side inverter control scheme. The grid side inverter control works to maintain the DC-link capacitor voltage at the set value, so that the active power can be exchanged efficiently from PMSG to the grid. It also controls the reactive power output to the grid in order to control the grid side voltage. In this control strategy, the d-axis of

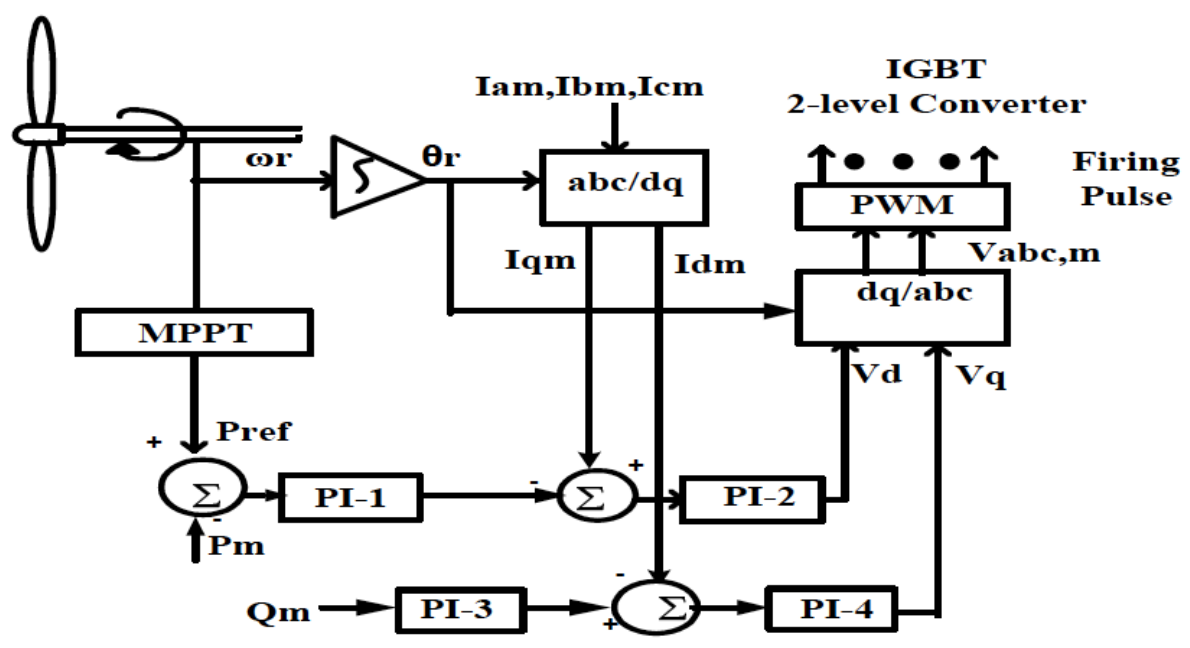

(a)

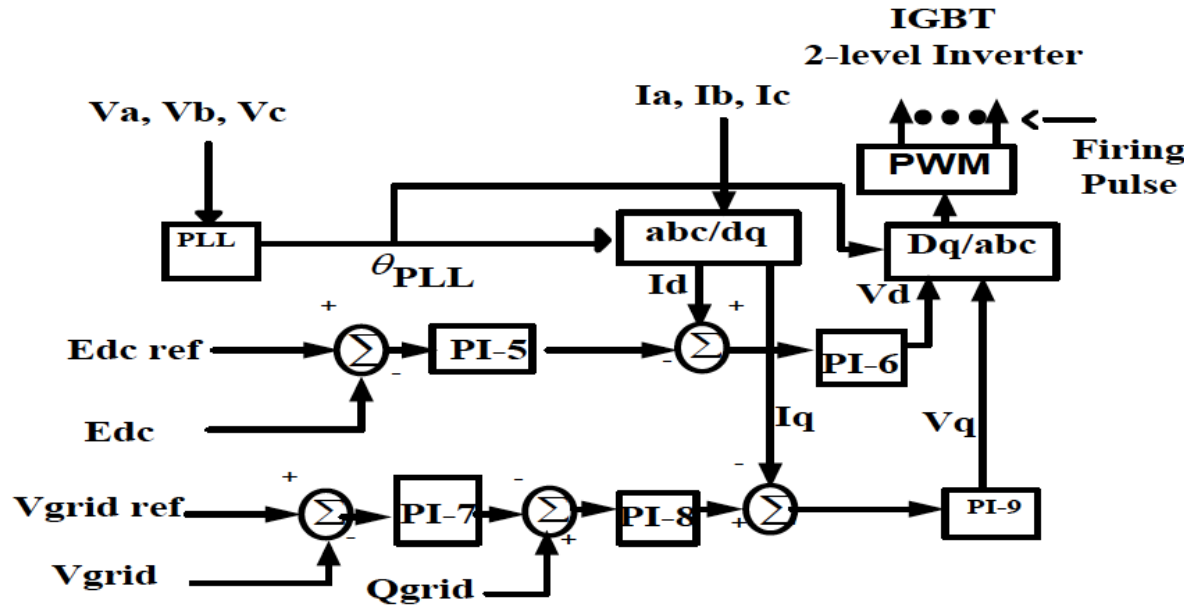

(b)

Figure 4: Control structure for (a) generator side frequency converter (b) grid side frequency inverter. 
the reference frame is oriented along the grid side voltage. Therefore, active and reactive power can be expressed as [12].

$$
\begin{gathered}
P_{\text {grid }}=\left(V_{d \_ \text {_rid }}\right) *\left(I d \_ \text {grid }\right) \\
\text { Qgrid }=-\left(V_{d} \_ \text {grid }\right) *(I \text { I_grid })
\end{gathered}
$$

The control structure for the grid side inverter also has two branches. One branch is for DC link voltage control (PI-5 and PI-6) and the other is for the grid side voltage control (PI-7 to PI-9). In order to assure the active power exchange from PMSG to grid, the voltage of DC link capacitor, $E_{d c}$, is controlled by the d-axis current component, $I_{d g r i d}$, of the grid. Again, the q-axis current component of the grid, $I_{\text {qgrid }}$, can control the reactive power, $Q_{\text {grid }}$, of the grid side inverter.

\subsection{Combination of IG and PMSG}

In this paper, a comparison for both dynamic and transient stability augmentation capability between Induction Generator (IG) and Permanent Magnet Synchronous Generator (PMSG) has been explained. Different combinations of wind farm considering IG and PMSG have been considered in this study for a total capacity of $6 \mathrm{MW}$. The simulation results show that the performances of IG can be improved by including PMSG with IG, without using any controlling devices. The scheme used for this combination is shown in Figure 5.

\section{METHOD OF CALCULATING POWER SYSTEM FREQUENCY [13]}

In this study, power system frequency is considered as the index for smoothing effect in dynamic analysis. Power system frequency fluctuation is occurred due to unbalance between supply and load power in power system. Then, the frequency fluctuation can be described by using two components, the rate of generator output variation, $\mathrm{K}_{\mathrm{G}}[\mathrm{MW} / \mathrm{Hz}]$, and load variation, $\mathrm{K}_{\mathrm{L}}[\mathrm{MW} / \mathrm{Hz}]$ respectively. They are representing the amount of power variation causing $1[\mathrm{~Hz}]$ frequency fluctuation. When generator output variation, $\Delta G[\mathrm{MW}]$, and load variation, $\Delta \mathrm{L}[\mathrm{MW}]$, are occurred, frequency fluctuation of the power system, $\Delta \mathrm{F}[\mathrm{Hz}]$, is expressed as follows.

$$
\Delta \mathrm{F}=\frac{\Delta \mathrm{G}-\Delta \mathrm{L}}{\mathrm{KG}_{\mathrm{G}}+\mathrm{KL}_{\mathrm{L}}}
$$

$\mathrm{K}=\mathrm{K}_{\mathrm{G}}+\mathrm{K}_{\mathrm{L}}$

Where, $\mathrm{K}$ is frequency characteristic constant. In general, frequency characteristic is expressed as percentage $\mathrm{K}_{\mathrm{G}}$ (expressed as $\% \mathrm{~K}_{\mathrm{G}}$ ) for the total capacity of all generators and percentage $\mathrm{K}_{\mathrm{L}}$ (expressed as $\% \mathrm{~K}_{\mathrm{L}}$ ) for the total load. In general, it is known that $\% \mathrm{~K}_{\mathrm{G}}$ and $\% \mathrm{~K}_{\mathrm{L}}$ are almost constant and generally take a value of $8-15[\% \mathrm{MW} / \mathrm{Hz}]$ and 2-6 [\%MW/Hz] respectively. However, $\mathrm{K}_{\mathrm{L}}$ and $\mathrm{K}_{\mathrm{G}}$ change greatly during a day because the number of parallel generators changes depending on the amount of load during a day. And, when power imbalance $\Delta P$ is occurred in power system, frequency fluctuation $\Delta \mathrm{P} / \mathrm{K}$ cannot occur immediately due to the governor characteristic and generator inertia. Normally, $\Delta \mathrm{F}$ converges to a new steady state value in 2 to 3 [sec]. In general, when $\Delta \mathrm{P}$ is changing slowly, relationship between $\Delta \mathrm{P}$ and $\Delta \mathrm{F}$ can be expressed as follows.

$$
\frac{\Delta \mathrm{F}}{\Delta \mathrm{P}}=\frac{1}{\mathrm{~K}(1+\mathrm{sT})}
$$

Where, $\Delta \mathrm{P}=\Delta \mathrm{G}-\Delta \mathrm{L}$. Since changing load is not considered in this study, $\Delta \mathrm{L}$ is " 0 ". Time constant, $\mathrm{T}$

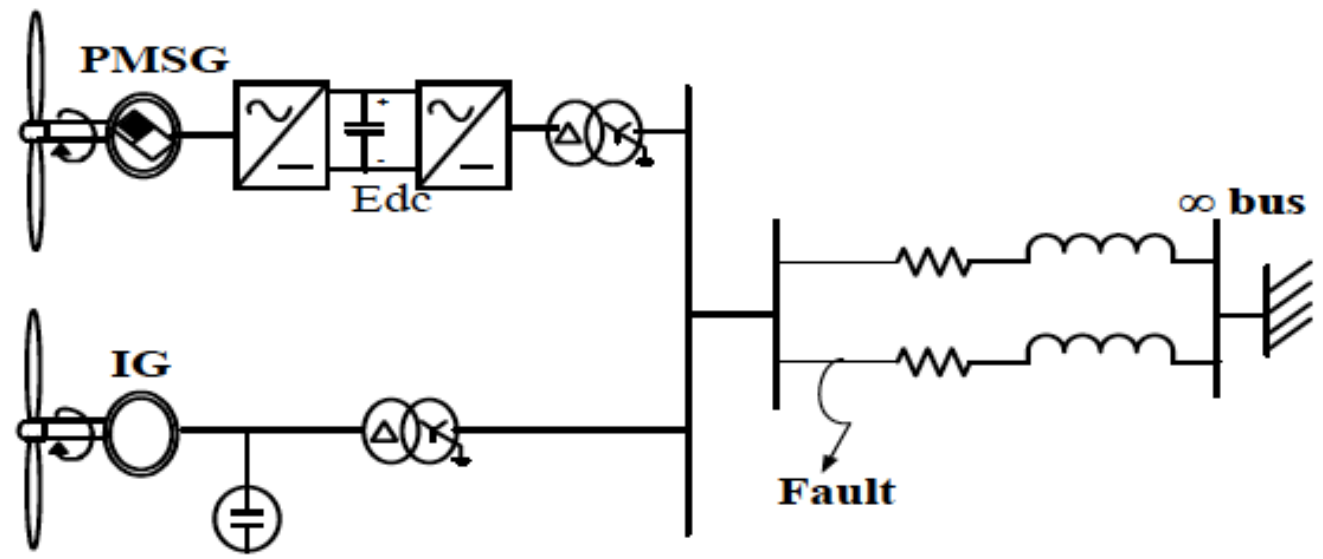

Figure 5: Wind farm model with both IG and PMSG. 
[sec], depending on the setting of generator governor and generator inertia, is generally 3 to $5[\mathrm{sec}]$. In this study, power system capacity is assumed to be $6[\mathrm{MW}]$ and frequency characteristic $\mathrm{K}[\mathrm{MW} / \mathrm{Hz}]$ is selected to 8 $[\mathrm{MW} / \mathrm{Hz}]$. This selection means that adjustability of the system frequency is weak, resulting a severe situation. Similarly, time constant $\mathrm{T}$ is selected to 3 [sec]. In this study, frequency fluctuation in power system is evaluated by using Eq. 13. Therefore, frequency fluctuation, $\Delta \mathrm{F}$, is obtained as shown in Figure $\mathbf{6}$.

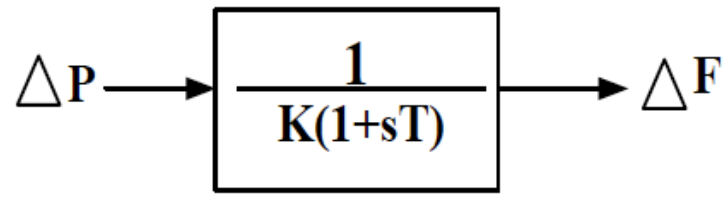

Figure 6: Frequency calculation model.

\section{SIMULATION RESULTS}

Simulations have been done by using Power System Computer Aided Design / Electromagnetic Transient including DC (PSCAD/EMTDC) program [11] for 350 seconds. The timing step of the simulation is chosen to be $0.01 \mathrm{sec}$. Here three case studies have been considered to verify the effectiveness of the proposed wind farm scheme. In case-1, a PMSG of 6 MVA is operated alone, in case-2 IG of 6 MVA is operated alone and in case-3, PMSG of 3 MVA and IG of 3 MVA are operated together. Their performances in both dynamic and transient conditions have been compared.

\subsection{Dynamic Stability Analysis}

Figure 7 shows the variable wind speed data used in the simulation. Figure 8 shows the grid side voltage response for the three cases. It is seen that the terminal voltage of the wind farm containing both IG and PMSG can be maintained at a constant rated value

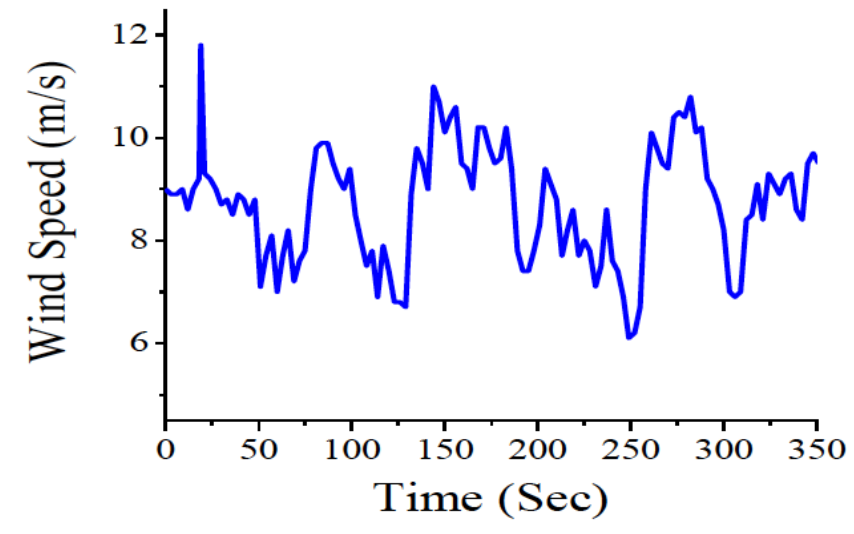

Figure 7: Wind speed data. or at the desired level, for which no FACTS devices are needed. The base value for voltage is $66 \mathrm{KV}$.

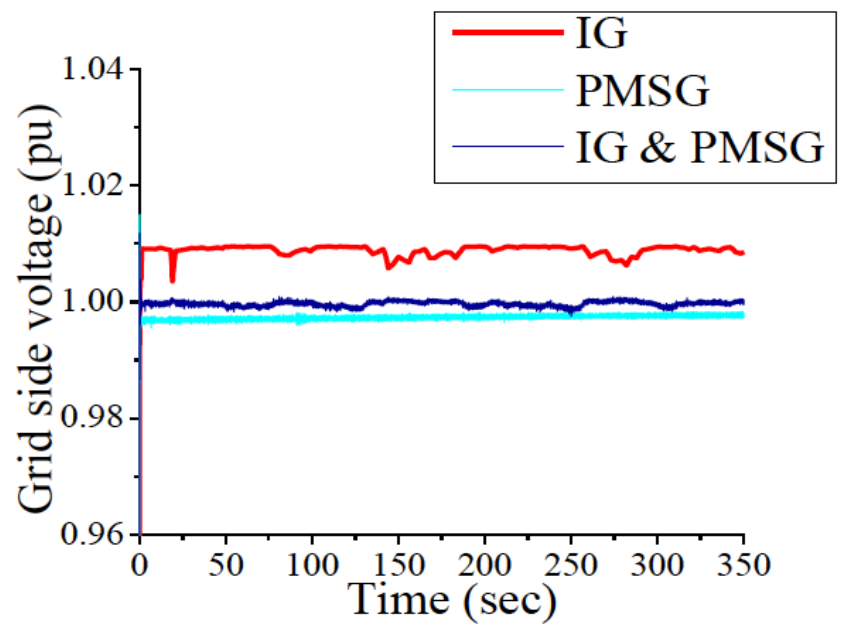

Figure 8: Grid side voltage.

Figures 9 and 10 show the real power, $\mathrm{P}$, and reactive power, $Q$, available at the grid side respectively. The PMSG, in spite of varying wind speed, maintains a constant desired value of the real power at the grid and the proposed control strategy provides reactive power compensation which can not be obtained without external controlling devices in conventional wind farm. Here, the per unit value of powers are shown, the base value is $6 \mathrm{MW}$ for all cases. The frequency response at the grid side is shown in Figure 11. Here also PMSG helps to attain a stable frequency response with IG.

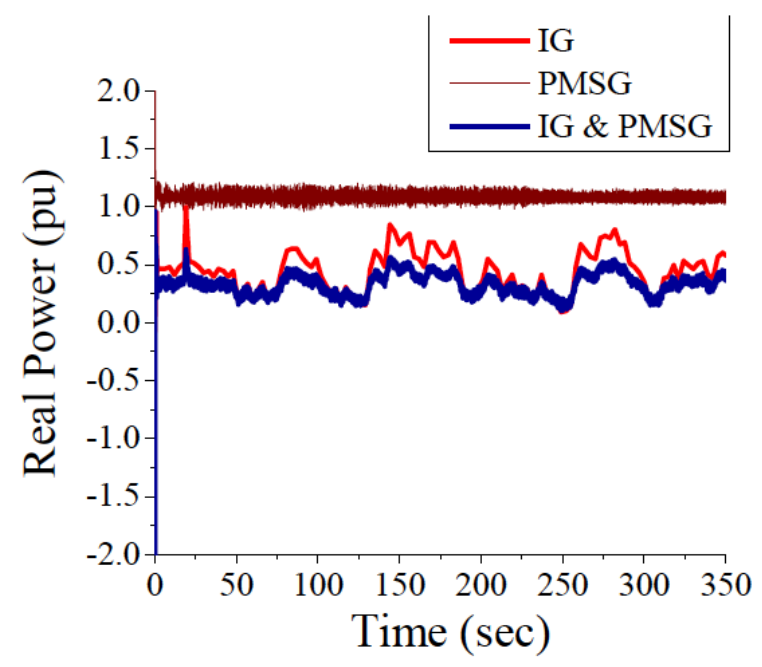

Figure 9: Real power at the grid side.

\subsection{Transient Stability Analysis}

In this study, the dynamic wind speed data shown in Figure $\mathbf{7}$ is used for transient stability analysis to make 


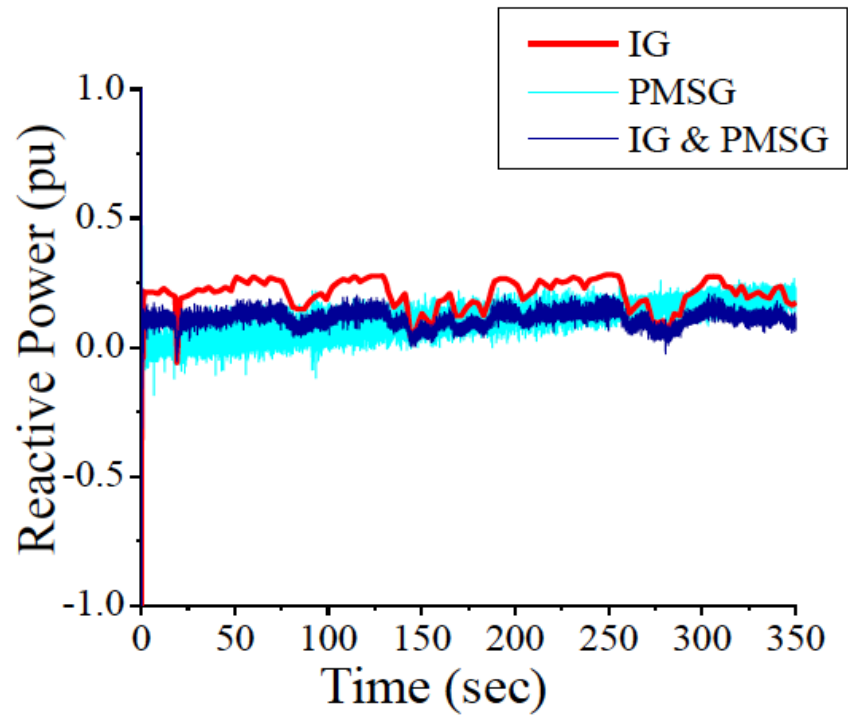

Figure 10: Reactive power at the grid side.

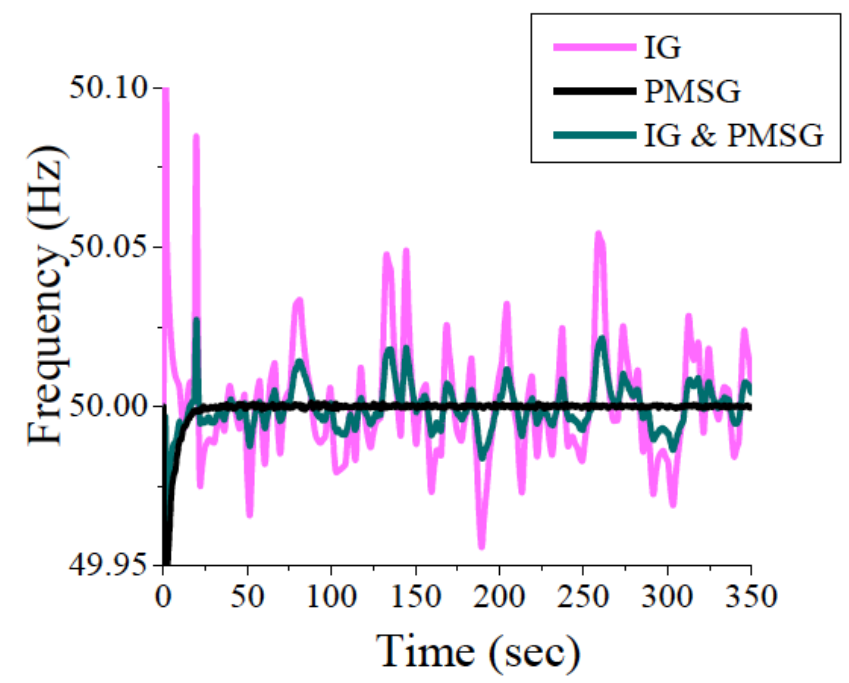

Figure 11: Frequency response $(\mathrm{Hz})$.

the response of the proposed system more practical. For this, a three line to ground ( $3 L G$ ) fault has been considered, which occurs at $35 \mathrm{~s}$, and the fault is cleared within $0.05 \mathrm{~s}$. Rotor speed of IG and PMSG during their combined operation is shown in Figure 12. The grid side voltage is shown in the Figure 13. For IG, the grid side voltage varies and its transient response is not acceptable, but the transient stability of the farm is quite improved by using both PMSG and IG. The base value for grid side voltage is $66 \mathrm{KV}$.

Figures 14 and 15 show the real power and reactive power available at the grid side respectively. The PMSG based wind farm provides the necessary reactive power compensation for IG during fault and ensures the active power exchange to the grid. The base value is $6 \mathrm{MW}$.

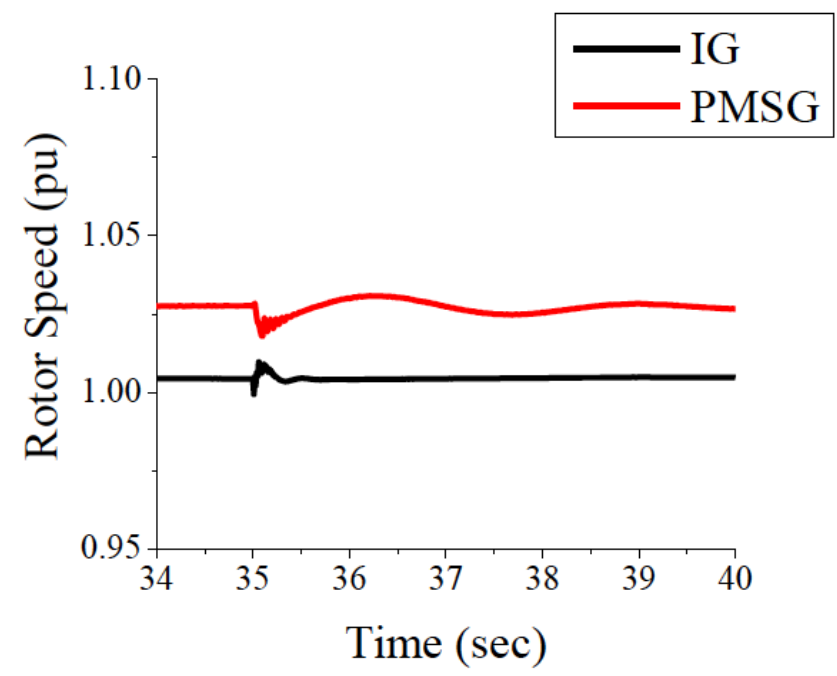

Figure 12: Rotor speed during fault.

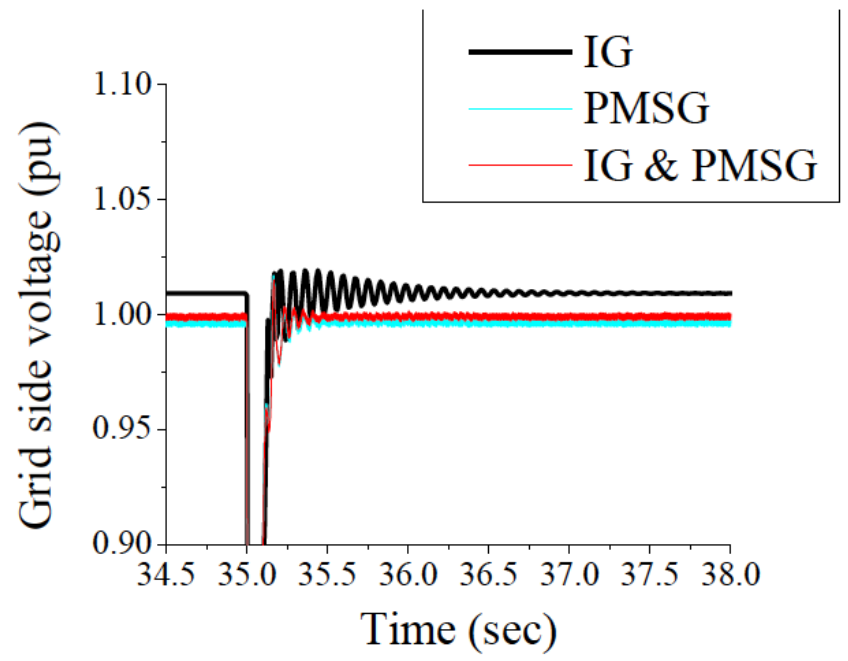

Figure 13: Grid side voltage during fault.

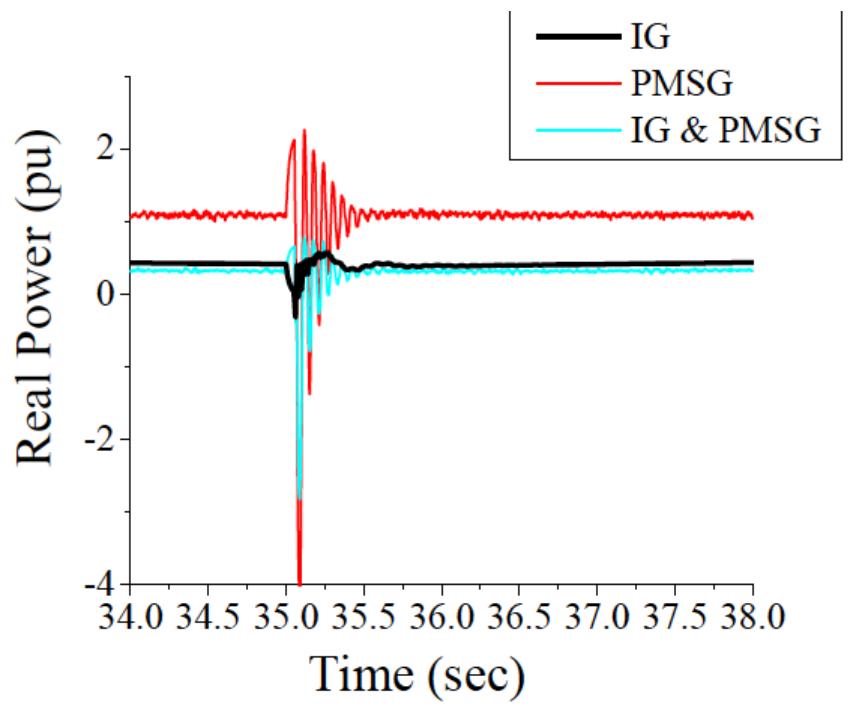

Figure 14: Real power during fault. 


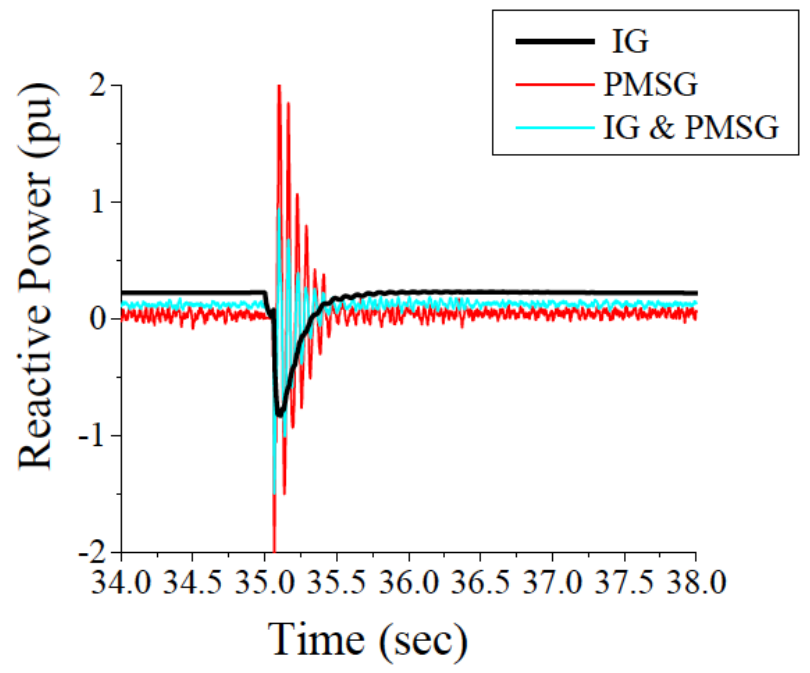

Figure 15: Reactive power during fault.

So, it is seen that PMSG has a better and efficient stability that can ensure the reliable operation of a fixed speed IG based wind farm. These simulation results show the effectiveness of the proposed wind farm during both dynamic and transient conditions.

\section{CONCLUSION}

PMSG itself has a wonderful response when used in a wind farm. But PMSG alone can not be used for large scale wind turbines due to its drawbacks, like, high price of the magnet and the chances of the permanent magnet to get de-magnetized at high temperature etc. Hence, an interesting alternative may be the mixed combination of IG and PMSG. Thus, the drawbacks of both IG and PMSG can be avoided and also the need for the non producing external controlling devices can be eliminated. The simulation results prove the ability of the proposed control topology. This method is equally effective for both new wind farms and for existing wind farms where expansion of installed capacity is required. Finally, it is concluded that, the proposed system is a good tool for power system stability improvement by contributing to the electrical output and eliminating the costs of external controlling devices.

\section{REFERENCES}

[1] Global Wind Energy Council. Global Wind Report Annual market update 2012. [retrieved 23 April 2013]. Available from: http://www.gwec.net/publications/global-wind-report2/global-wind-report-2012/

[2] Rosyadi M, Sheikh MRI, Muyeen SM, Takahashi R, Tamura J. A Control Strategy of Direct-Drive Permanent Magnet Wind Generator for Wind Farm Stabilization. Proceedings of the Annual Paper Meeting, Society of Rotatory Mission, Japan 2010; pp. 7-12.

[3] Sheikh MRI, Tasneem Z. Modeling and Optimization of Variable Speed Wind Turbine Using Permanent Magnet Synchronous Generator. Proceedings of the 1st International Conference on Mechanical, Industrial and Materials Engineering 2013 (ICMIME 2013), 1-3 November 2013, RUET, Rajshahi, Bangladesh, on page(s): 245-250.

[4] Tasneem Z, Sheikh MRI. Modeling and Controlling of a Directly Driven Wind Turbine Using Permanent Magnet Synchronous Generator. Proceedings of the 1st International Conference on Mechanical, Industrial and Materials Engineering 2013 (ICMIME 2013), 1-3 November 2013, RUET, Rajshahi, Bangladesh, on page(s): 261-267.

[5] Melicio R, Mendes VMF, Catalao JPS. Computer simulations of a converter control malfunction on PMSG-based wind turbines. Proceedings of the International Conference on Computer as a Tool (EUROCON), 2011 IEEE. Page(s):1-4. http://dx.doi.org/10.1109/EUROCON.2011.5929153

[6] Muyeen SM, Takahashi R, Murata T, Tamura J. A Variable Speed Wind Turbine Control Strategy to Meet Wind Farm Grid Code Requirements. IEEE Transactions on Power Systems 2010; 25(1). http://dx.doi.org/10.1109/TPWRS.2009.2030421

[7] Muyeen SM, Takahashi R, Tamura J. Operation and Control of HVDC-Connected Offshore Wind Farm. IEEE Transactions on Sustainable Energy 2010; 1(1).

[8] Heier S. Grid Integration of Wind Energy Conversion System, John Wiley \& Sons Ltd., 1998.

[9] Sheikh MRI, Muyeen SM, Takahashi R, Murata T, Tamura J. International Review of Automatic Control (IREACO) 2008; 1(3): 311

http://dx.doi.org/10.1541/ieejpes.126.742

[10] Muyeen SM, Tamura J, Murata T. Stability Augmentation of a Grid-connected Wind Farm. 1st edition. Green Energy and Technology, Springer-Verlag: London, UK 2009.

[11] PSCAD/EMTDC Manual, Manitoba HVDC Research Center 1994.

[12] Fernandes LM, Garcia CA, Jurado F. Operating Capability as a $P Q / P V$ node of a Direct-Drive Wind Turbine based on a permanent magnet synchronous generator. Journal of Renewable Energy 2010; 35: 1308-1318. http://dx.doi.org/10.1016/j.renene.2009.11.046

[13] Sheikh MRI. Stabilization of a Grid Connected Wind Farm by Using SMES. a Ph.D thesis, Kitami Institute of technology, Japan. September 2010. Available from: https://kitir.lib.kitamiit.ac.jp/dspace/bitstream/10213/1744/1/Sheikh.pdf. 